\title{
The 2-Deoxyglucose Test as a Supplement to Fasting for Detection of Childhood Hypoglycemia
}

\author{
INGER L. HANSEN, MARILYN M. LEVY, AND DOUGLAS S. KERR ${ }^{(43)}$ \\ Department of Pediatrics, Rainbow Babies and Childrens Hospital, Case Western Reserve University, \\ Cleveland, Ohio, USA
}

\begin{abstract}
Summary
The acute response to simulated hypoglycemia induced by 2deoxyglucose (2DG) was compared with the prolonged fasting test as a possible screening test for detection of childhood hypoglycemia. Ten children, ages 2-9 yr, without a documented history of hypoglycemia were classified retrospectively as reference subjects. While fasting, their plasma glucose decreased to an average of $50 \mathrm{mg} / \mathrm{dl}$ (range, 30-74) between 28-36 h. After infusion of 2DG, $50 \mathrm{mg} / \mathrm{kg}$ IV over $30 \mathrm{~min}$, their plasma glucose increased by an average of $35 \mathrm{mg} / \mathrm{dl}$ (range, 19-56) between 60$120 \mathrm{~min}$. The half-life of plasma 2DG was $48 \mathrm{~min}$.

Twenty-three other children in the same age range had an abnormal response to one or both of these tests. Thirteen of these children became definitely hypoglycemic while fasting (glucose $<30 \mathrm{mg} / \mathrm{dl}$ ) and also failed to increase their plasma glucose by more than $10 \mathrm{mg} / \mathrm{dl}$ after 2DG. Five children had plasma glucose values between $30-40 \mathrm{mg} / \mathrm{dl}$ during the first $24 \mathrm{~h}$ of fasting that were associated with a change in mental status but responded to 2DG with an increase in plasma glucose. The remaining five subjects had an apparently normal response to fasting but did not respond to 2DG; two of these had documented spontaneous hypoglycemia. No cases of documented hypoglycemia were undetected by either test. It is concluded that the 2DG test is a short safe supplement to fasting which is equally effective as the prolonged fasting test in detecting hypoglycemia. Neither test alone is completely reliable, but the combination is complementary.
\end{abstract}

\section{Abbreviation}

2DG, 2-deoxyglucose

The most direct approach to confirming a suspected diagnosis of spontaneous hypoglycemia is to measure blood glucose at the time of symptoms and, if possible, to demonstrate that symptoms are rapidly relieved after the blood glucose has been increased. This obvious approach is very often not successful in children because hypoglycemia is typically sporadic, brief, and may not be associated with definitive symptoms. When blood glucose values are obtained they may be equivocal. For these reasons, follow-up testing is frequently required to establish or confirm the diagnosis of hypoglycemia.

Hypoglycemia in children due to various etiologies commonly occurs while fasting, and therefore fasting has been the most widely recommended general screening test $(4,10)$. If properly conducted, observations made during the fasting test can lead to a specific differential diagnosis in the event that the child does become hypoglycemic; however, as a test procedure, fasting has several practical disadvantages. Because the test may need to be continued for as long as $36 \mathrm{~h}$ or until the child becomes definitely hypoglycemic, it is inevitably difficult and not without risk. Interpretation may be complicated by choice of appropriate reference standards and a variable relationship between blood glucose and symptoms (16). An especially frustrating outcome is to find that some children with documented spontaneous fasting hypoglycemia may fail to be distinguished from normal children under conditions of hospital testing (3).

The possibility of using 2DG as a general screening test for initial detection of childhood hypoglycemia was suggested by observations that children with apparent "ketotic" hypoglycemia fail to respond to $2 \mathrm{DG}$. This was first reported by Sizonenko $e t$ al. (33) and subsequently confirmed by ourselves and others (16, 19). Considerable experience has been gained by use of $2 D G$ as a test in adults and in experimental animals. Originally proposed as an inhibitor of glycolysis and possible anti-cancer agent, 2DG administered to humans was found to result in hyperglycemia $(5,21)$. At the dose level most commonly used, 2DG does not result in direct general inhibition of glucose metabolism. The hyperglycemic response is the result of central inhibition of glucose transport in the hypothalamus (27). This results in acute sympathoadrenal $(1,16,23,25,38)$, anterior pituitary $(1,25$, $39)$, vagal $(7,13)$, and appetite responses $(7,23,24,34,38)$ that are similar to those produced by insulin without the superimposed peripheral effects of insulin. The normal counter-regulatory response includes increases in plasma glucose, free fatty acids, lactate, epinephrine, cortisol, and suppression of insulin $(1,23,25,38)$.

The objective of the present study was to compare the relative reliability of the fasting test with the 2DG test in the initial detection of childhood hypoglycemia. The children tested included a spectrum of cases referred for evaluation of suspected or known hypoglycemia and a few siblings recruited as possible controls. Because of the limited availability of normal controls, test results were classified retrospectively and criteria selected to determine whether there was sufficient evidence to support a diagnosis of hypoglycemia.

\section{MATERIALS AND METHODS}

Subjects. Most of the subjects tested were referred for evaluation of suspected or previously confirmed hypoglycemia (29 children); a few cases were recruited who were twin siblings of hypoglycemic subjects (four children). Infants under $1 \mathrm{yr}$ and children over 10 -yr-old are not included in this series. The average age of the subjects was $4 \frac{1}{2} \mathrm{yr}$, with a range of $2-9 \mathrm{yr}$ (Table 1). The subjects were classified retrospectively on the basis of clinical history and responses to the tests, as will be described below. The ages, sex, and physical characteristics of the reference and hypoglycemic groups were not significantly different (Table 1). Informed parental consent was obtained after explanation of possible risks and the investigational nature of the $2 \mathrm{DG}$ test. 
Table 1. Clinical characteristics of children tested

\begin{tabular}{lcc}
\hline & $\begin{array}{c}\text { Reference } \\
\text { subjects }\end{array}$ & $\begin{array}{c}\text { Hypoglycemic } \\
\text { subjects }\end{array}$ \\
\hline Number & 10 & 23 \\
Males/females & $6 / 4$ & $13 / 9$ \\
Age (yr)* & $4.8(2-9)$ & $4.4(2-9)$ \\
Height age (yr) ${ }^{*}$ & $3.9(11 / 2-10)$ & $3.7(11 / 2-10)$ \\
$\quad$ Weight & $97(92-104)$ & $98(75-129)$ \\
\hline Expected wt/ht & & \\
\hline
\end{tabular}

* Average (range).

$\dagger$ Height age, age equivalent of 50 th percentile height.

$\ddagger$ Expected wt/ht, 50th percentile weight for height.

Approval for use of 2DG was obtained from the Food and Drug Administration.

Test procedures. The fasting test consisted of withholding food and allowing only water until either the subject became hypoglycemic or until plasma glucose decreased to a constant basal value for 6-8 h with large acetonuria. Hypoglycemia was defined as: 1) plasma glucose below $30 \mathrm{mg} / \mathrm{dl}$ at any time or 2) plasma glucose below $40 \mathrm{mg} / \mathrm{dl}$ associated with significant symptoms indicative of a change in mental status (inappropriate drowsiness, irritability, confusion, or unresponsiveness). Blood samples were obtained at 2-h intervals during the fasting test from an indwelling intravenous needle for rapid determination of glucose.

The 2DG test was performed at a separate time before or after the fasting test (from a few days to several months apart). Several days of typical food intake were required before the test but a specific diet plan or food record was not used. The test was started after an overnight fast of 10-14 h. Baseline blood samples were obtained at 30-min intervals from an indwelling needle and plasma glucose determined rapidly. If the plasma glucose was above $60 \mathrm{mg} / \mathrm{dl}$ during the $30-\mathrm{min}$ baseline period, then 2DG was infused intravenously over $30 \mathrm{~min}$ (total dose, $50 \mathrm{mg} / \mathrm{kg}$ ). Blood sampling was continued at 30 -min intervals for 2 more $\mathrm{h}$ to determine plasma glucose and 2DG. Blood pressure, pulse, respirations, and temperature (oral or axillary) were determined at 30-min intervals and any change in mental status or symptoms noted. At the end of $2 \mathrm{~h}$ the test was terminated by administration of glucose, $500 \mathrm{mg} / \mathrm{kg}$ intravenously, after which time the child was allowed to eat.

Materials and analytical methods. 2DG was obtained from Sigma Chemical Co. (F and D Division, St. Louis, MO). A 5\% aqueous solution was prepared in the hospital pharmacy, filter sterilized, cultured, tested for pyrogens, and assayed before use. The concentration of 2DG did not decrease upon storage of solutions for as long as $5 \mathrm{yr}$; for clinical use, solutions were not kept for more than $1 \mathrm{yr}$ after preparation. Two methods were employed for determination of 2DG. A quantitative but nonspecific enzymatic method useful for pure solutions was adapted from determination of glucose with hexokinase, pyruvate kinase, and lactate dehydrogenase (31). In plasma, a colorimetric assay based on reaction with quinaldine was used (6); plasma (25 $\mu \mathrm{l}$ sample) was deproteinized with $5 \%$ perchloric acid $(1 \mathrm{ml})$, and a blank was prepared from plasma obtained before administration of 2DG. The molar extinction coefficient of this assay at $420 \mathrm{~m} \mu$ is approximately $1.0 \times 10^{3}$. The purity of $2 \mathrm{DG}$ was also confirmed by thin layer chromatography (20). Glucose was assayed in plasma with glucose oxidase by the rate of oxygen uptake method, using a Beckman Glucose Analyser. This method was found to be specific for glucose; 2DG in concentrations up to at least $50 \mathrm{mg} / \mathrm{dl}$ does not react and does not interfere with determination of glucose. All assays were run in duplicate.

\section{RESULTS}

Plasma glucose during the fasting test (Fig. 1). The reference range for plasma glucose in the fasting test was derived from 10 children who did not have a documented history of hypoglyce- mia, who tolerated the fasting test without developing definitely abnormal symptoms or a plasma glucose of less than $30 \mathrm{mg} / \mathrm{dl}$, and who had an increase of glucose after 2DG of at least $15 \mathrm{mg} /$ dl. The fast continued in each case until urine acetone became large and there was no further decline of plasma glucose for several hours. The length of fasting was continued for at least 36 $\mathrm{h}$ except for one subject, who fasted $29 \mathrm{~h}$. After $8 \mathrm{~h}$ of fasting the average plasma glucose concentration of this group was $85 \mathrm{mg} /$ $\mathrm{dl}$ (range, 64-98 mg/dl). Plasma glucose decreased gradually over $28 \mathrm{~h}$ and then remained relatively constant around an average of $50 \mathrm{mg} / \mathrm{dl}$ (range, $30-74 \mathrm{mg} / \mathrm{dl}$ ). In four subjects who were fasted for $40 \mathrm{~h}$ there was no further decrease of glucose.

In 13 children plasma glucose decreased below $30 \mathrm{mg} / \mathrm{dl}$ while fasting (Fig. 1, solid circles). Hypoglycemia occurred at times varying from as early as $9 \mathrm{~h}$ to as late as $35 \mathrm{~h}$ of fasting. Two subjects became hypoglycemic after $24 \mathrm{~h}$ of fasting with a subsequent increase of plasma glucose to above $30 \mathrm{mg} / \mathrm{dl}$ before the fast was terminated. Twelve of these children also had a documented history of spontaneous symptomatic hypoglycemia.

In five children, plasma glucose fell within the first $24 \mathrm{~h}$ of fasting to between $30-40 \mathrm{mg} / \mathrm{dl}$, below the reference range (Fig. 1 , solid squares). The test was terminated because significant symptoms developed that indicated a change in mental status (see Test procedures). In four of these children there was some degree of recovery of plasma glucose before the test was terminated. Prior spontaneous episodes of documented fasting hypoglycemia had occurred in three of these cases.

The five remaining children maintained their plasma glucose within the range of the reference subjects under the conditions of the fasting test (Fig. 1, solid triangles). Three of these subjects had no symptoms during the fasting test and two had only mild transient symptoms without a change in mental status. Two of these subjects had a definite history of previously documented spontaneous hypoglycemia and two had a very suggestive, but undocumented history. The difference between the previous history of spontaneous hypoglycemia and the apparently normal hospital fasting test might have reflected a real change in the

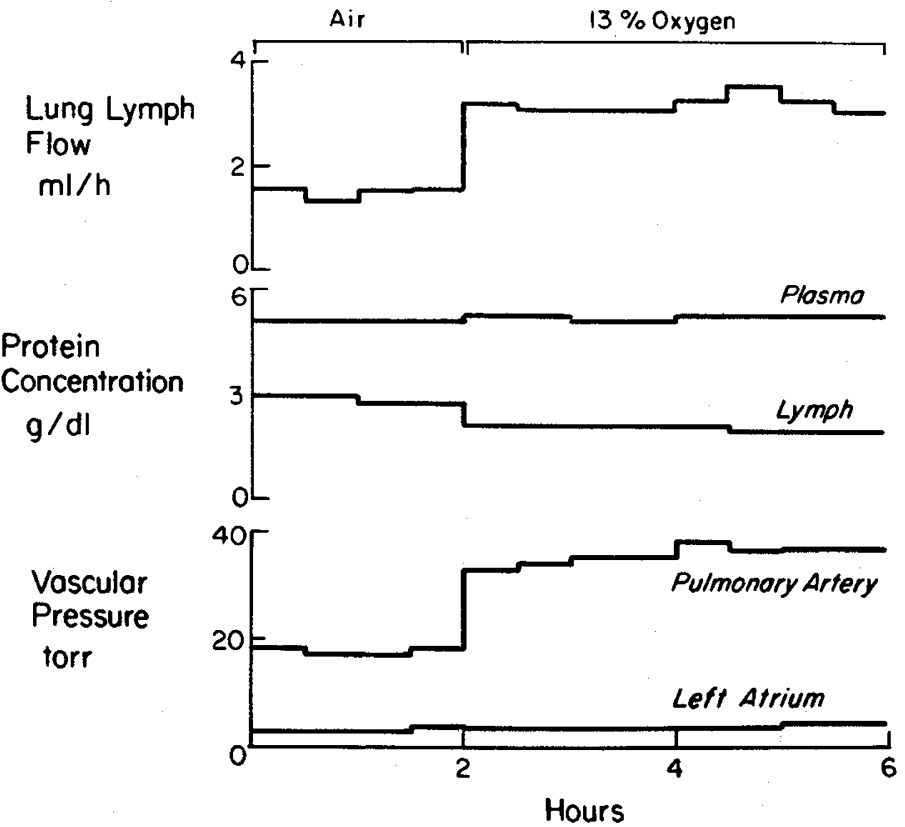

Fig. 1. Time course of plasma glucose while fasting. The line, bars, and shaded area correspond to the averages, standard deviations, and ranges of values for the 10 reference children. The individual closed circles, squares, and triangles correspond to the minimum glucose value observed in each of the 23 other children (see "Results"). The dotted lines indicate subsequent increases of plasma glucose in those cases in which the minimum value was not the final observation. 


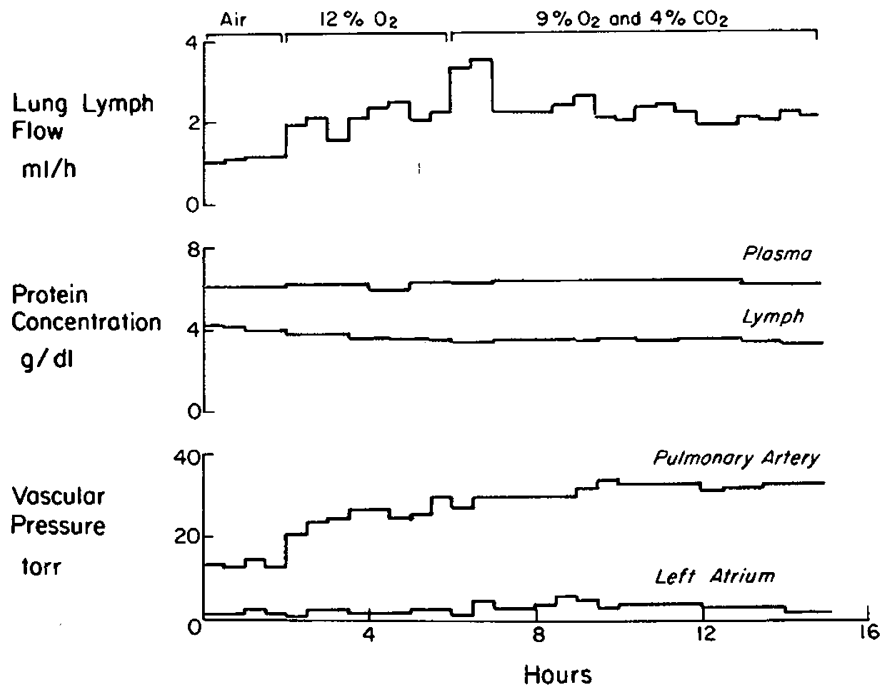

Fig. 2. Time course of change of plasma glucose after 2-deoxyglucose. The line, bars, and shaded area correspond to the averages, standard deviations, and ranges of values observed in the 10 reference children.

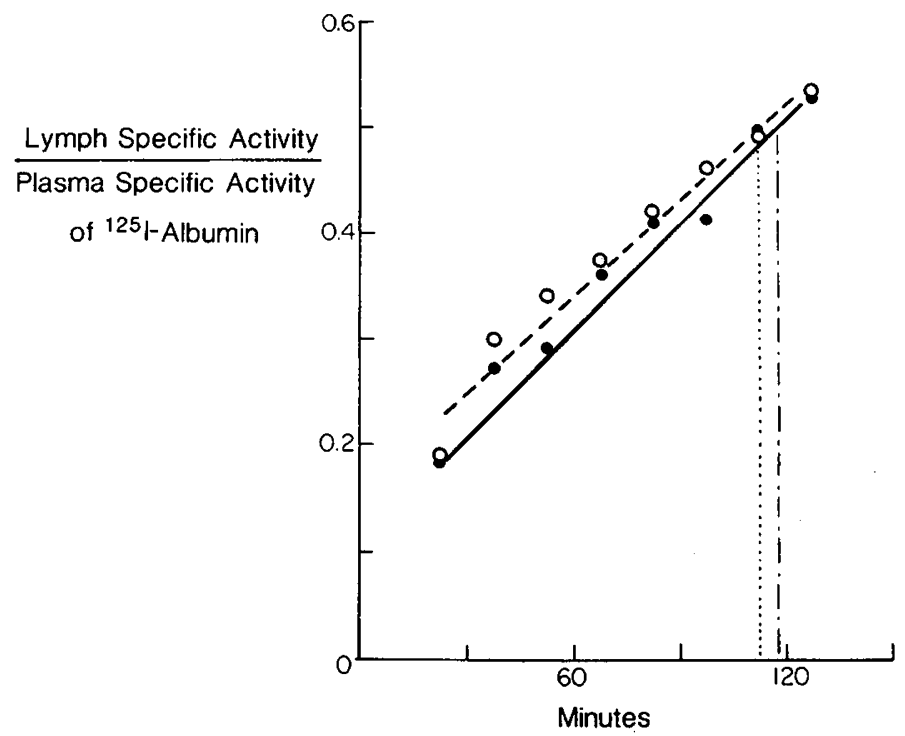

Fig. 3. Average change of plasma glucose after 2-deoxyglucose. Each point represents the difference between the average of plasma glucose values from $60-120 \mathrm{~min}$ and those obtained during the 30-min baseline period. The open circles, bar, and shaded area correspond to the individual values, average, standard deviation, and range of the reference group. The closed circles, squares, and triangles correspond to the same individuals as in Figure 1.

child's susceptibility to fasting hypoglycemia. This is not a completely sufficient explanation because, in at least one case, documented spontaneous hypoglycemia recurred after the fasting test.

Plasma glucose after 2DG. After infusion of 2DG $(50 \mathrm{mg} / \mathrm{kg}$ over $30 \mathrm{~min}$ ) in the 10 reference subjects, plasma glucose increased by an average of $37 \mathrm{mg} / \mathrm{dl}$ over $60 \mathrm{~min}$ and remained relatively constant over the next hour (Fig. 2). The increase was calculated for each individual as the difference between the average glucose concentration at $-30-0 \mathrm{~min}$ before $2 \mathrm{DG}$ and the average of glucose values at 60,90 , and $120 \mathrm{~min}$ after starting the $2 \mathrm{DG}$ infusion. For the 10 reference subjects the average increase was $35 \mathrm{mg} / \mathrm{dl}$ (range, 19-56) (Fig. 3).

Among the 13 children whose plasma glucose fell below 30 $\mathrm{mg} / \mathrm{dl}$ under conditions of the fasting test, there were no individuals who had an increment of plasma glucose after 2DG of more than $10 \mathrm{mg} / \mathrm{dl}$ (Fig. 3, solid circles). The average plasma glucose in this group did not increase, and in many subjects glucose gradually decreased reflecting the superimposed effects of fasting and lack of response to 2DG.

Among the remaining 10 children, the response to fasting and to 2DG were inconsistent. The five children with relatively early onset of milder hypoglycemia in the fasting test had increases in plasma glucose after 2DG that ranged from $12-59 \mathrm{mg} / \mathrm{dl}$ (Fig. 3, solid squares). Only one of these subjects' response was below the range of the reference group. The five children whose fasting test had been apparently normal all failed to respond to 2DG (Fig. 3, solid triangles). These individuals therefore lacked the normal response to simulated hypoglycemia, although their defect was not evident under the conditions of the fasting test.

Plasma $2 D G$ concentration. At the end of the 30 -min infusion of $2 \mathrm{DG}$, the average plasma concentration of $2 \mathrm{DG}$, measured in 24 of the 34 children, was $11.7 \pm 0.7 \mathrm{mg} / \mathrm{dl}( \pm$ SEM) (Fig. 4). There was no significant difference in the plasma 2DG concentration of the children who responded with an increment in plasma glucose of $15 \mathrm{mg} / \mathrm{dl}$ or more and those who did not. The average initial plasma glucose concentration in the 14 children who responded was $79 \mathrm{mg} / \mathrm{dl}$ compared with $76 \mathrm{mg} / \mathrm{dl}$ in the 19 children who did not respond. The differences in glucose responses of these subjects cannot be attributed to differences in the relative initial concentrations of glucose or 2DG. Between 30-60 min, after the 2DG infusion had stopped, the concentration of $2 \mathrm{DG}$ decreased more rapidly. After $60 \mathrm{~min}$ the disappearance rate was first order with a half-life of $48 \mathrm{~min}$. At the end of 120 min the plasma concentration of $2 \mathrm{DG}$ was $16 \%$ of the initial value. After $6 \mathrm{~h}, 23 \%$ of the injected dose of 2DG had appeared in the urine of 11 of the subjects tested.

Signs and symptoms associated with the fasting and $2 D G$ tests. The frequency with which the children tested developed specific signs and symptoms during the fasting and the 2DG tests was similar (Table 2). The most common behavioral observation in either test was lethargy (drowsiness) and the next most common was irritability. Although these features were more frequent among children with abnormal responses to the fasting or 2DG tests, they also occurred among children in the reference group. More definite CNS changes of confusion, unresponsiveness, and seizures occurred under the test conditions only in children with definite hypoglycemia. Unresponsiveness occurred more frequently in the fasting than in the 2DG test. One child had a seizure while fasting (plasma glucose, $24 \mathrm{mg} / \mathrm{dl}$ ) and one had a seizure after 2DG. In the latter case, which was the third patient tested, the seizure occurred $1 \mathrm{~h}$ after starting the 2DG infusion. At that time plasma glucose was $26 \mathrm{mg} / \mathrm{dl}$. Rapid intravenous administration of glucose, $500 \mathrm{mg} / \mathrm{kg}$, stopped the seizure within

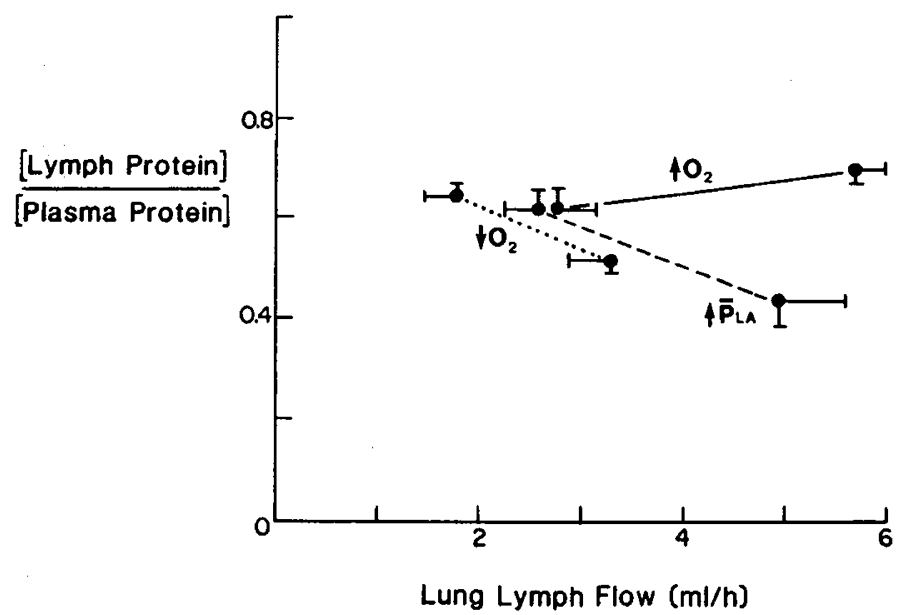

Fig. 4. Disappearance of plasma 2-deoxyglucose. The line and bars correspond to the mean values and standard errors. The initial samples were obtained at $30 \mathrm{~min}$ (at the end of the 2DG infusion). 
Table 2. Signs and symptoms associated with history, fasting, and 2-deoxyglucose tests*

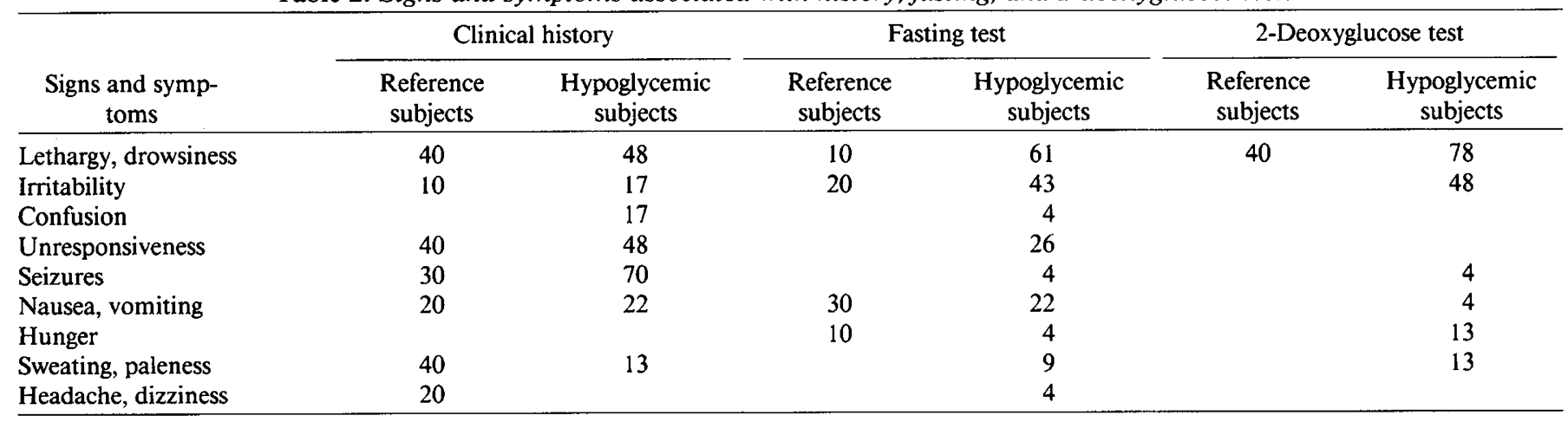

* Frequency of signs and symptoms expressed as percentage of children in group.

$1 \mathrm{~min}$ and the patient recovered promptly. Retrospectively, it was recognized that the initial plasma glucose concentration was only $40 \mathrm{mg} / \mathrm{dl}$. In subsequent tests, $2 \mathrm{DG}$ was not given unless the initial plasma glucose value was $>60 \mathrm{mg} / \mathrm{dl}$; with this precaution, no severe symptoms occurred.

It should be noted that there were no characteristic symptoms found in the clinical history that were particularly reliable in distinguishing children who subsequently were confirmed as having hypoglycemia from those who were not. Each of the children who responded abnormally to either the fasting or 2DG tests had a history of more severe symptoms of confusion, unresponsiveness, or seizures, but four of the 11 reference patients also had a history of these problems. None of the patients with hypoglycemia had a history of symptoms characteristic of an acute insulin reaction, such as nervousness, sudden hunger, sweating, and paleness.

There were no significant changes in pulse, respirations, or blood pressure after 2DG. Temperature (oral or axillary) decreased by $0.4^{\circ} \mathrm{C}$ among eight reference subjects in whom it was measured $(P<0.05)$; there was not a significant change of temperature in the other children tested.

\section{DISCUSSION}

In comparing the responses of these children to the fasting and 2DG tests, it is evident that although the results were consistent in the majority of cases, neither test alone was completely reliable in detecting children with hypoglycemia. It is not surprising that there is no single reliable definitive screening test for childhood fasting hypoglycemia because this is by nature an unpredictable, heterogeneous, and frequently unexplained disorder. The problems encountered in diagnosing hypoglycemia among adults are no less difficult $(8,26,30)$.

The diagnosis of hypoglycemia may be complicated by lack of clear definition of normal limits. During fasting, plasma glucose falls more rapidly to lower levels in children compared with adults. After $72 \mathrm{~h}$ of fasting, the average plasma glucose concentration in adults has been found to be $65-71 \mathrm{mg} / \mathrm{dl}$ (lower limits, $55 \mathrm{mg} / \mathrm{dl}$ ) in males, and $48-55 \mathrm{mg} / \mathrm{dl}$ (lower limits, $36 \mathrm{mg} / \mathrm{dl}$ ) in non-pregnant females $(8,12,26)$; values are lower for pregnant women. In one group of seven control infants ages 2-20 mo, selected for similar reasons as the present subjects, the average plasma glucose after $24 \mathrm{~h}$ of fasting was $52 \mathrm{mg} / \mathrm{dl}$ (range, 35-67) (35). In a larger group of 56 apparently normal children, ages $11 / 2-9 \mathrm{yr}$, the average blood glucose after $24 \mathrm{~h}$ of fasting was 52 \pm 14 (SD) $\mathrm{mg} / \mathrm{dl}$ ) (3). This range is similar to that found in the present series (considering the difference between plasma and blood), except for one reputedly normal subject in the former group who had a blood glucose value of $18 \mathrm{mg} / \mathrm{dl}$. With this single exception, there is good agreement between previous findings in infants and children and our reference group $(12,14,15$, $16,18,29,32)$. It is, therefore, reasonable to conclude that plasma glucose values between $30-40 \mathrm{mg} / \mathrm{dl}$ are not necessarily abnormal among infants and children who have fasted for $24 \mathrm{~h}$ or more, but values below $30 \mathrm{mg} / \mathrm{dl}$ are beyond normal limits.

In more than 100 reported $2 \mathrm{DG}$ tests $(50 \mathrm{mg} / \mathrm{kg})$ in normal adult subjects, the average increase of plasma glucose has been approximately $90 \mathrm{mg} / \mathrm{dl}(1,7,13,23,25,36,38,39,40)$. The lowest increase reported among 18 individual normal adult subjects was $26 \mathrm{mg} / \mathrm{dl}(23,38,39)$. Previous data concerning normal plasma glucose changes after $2 \mathrm{DG}$ in children are limited. Among six control children, apparently similar to the present reference group, the average increase in plasma glucose 60-120 min after 2DG was $60 \mathrm{mg} / \mathrm{dl}$, considerably higher than what was observed here. There was no response on the average among five hypoglycemic children (33). In another series, the increase of glucose after $2 \mathrm{DG}$ in five control children was $45 \pm 25$ (SD) $\mathrm{mg}$ / dl, but three hypoglycemic children failed to respond to $2 \mathrm{DG}$ (19). The average glucose increase of the present group of reference children is less than what has been found previously in children or adults, but the lower limits of the response is not inconsistent with previous data.

Although it was not possible to pre-select a group of normal control children, criteria of abnormality were based on a combination of clinical history and responses to the two tests. These criteria included the following: 1) a history of documented spontaneous hypoglycemia including symptoms associated with blood glucose $<40 \mathrm{mg} / \mathrm{dl}$; 2) a plasma glucose value during the fasting test $<30 \mathrm{mg} / \mathrm{dl}$ or below $40 \mathrm{mg} / \mathrm{dl}$ associated with significant symptoms (see "Materials and Methods"); and 3) an average increase of plasma glucose after $2 D G$ of $<15 \mathrm{mg} / \mathrm{dl}$. The 33 children tested were categorized retrospectively according to the outcome of these criteria of abnormality (Table 3 ). If none of the criteria were met, it was concluded that there was no evidence to make the diagnosis of hypoglycemia (reference subjects). If only one of the criteria was fulfilled, it was concluded that the child had a possible abnormality. If two or more of the criteria were fulfilled, it was concluded that a definite diagnosis of hypoglycemia could be made. According to this classification,

\begin{tabular}{lrccc} 
Table 3. Classification of subjects by evidence of abnormality \\
\hline $\begin{array}{c}\text { Final } \\
\text { classification }\end{array}$ & $n$ & $\begin{array}{c}\text { Spontaneous } \\
\text { hypo- } \\
\text { glycemia }\end{array}$ & $\begin{array}{c}\text { Fasting } \\
\text { test§ }\end{array}$ & $\begin{array}{c}\text { 2-Deoxy- } \\
\text { glucose } \\
\text { test } \|\end{array}$ \\
\hline No abnormality & 10 & 0 & 0 & 0 \\
Possible abnormality* & 4 & 0 & 1 & 3 \\
Definite hypoglycemia $\dagger$ & 19 & 18 & 17 & 16 \\
\hline
\end{tabular}

* Only one criteria of abnormality.

$\uparrow$ Two or more criteria of abnormality.

$\$$ Documented spontaneous hypoglycemia with definite symptoms and glucose $<40 \mathrm{mg} / \mathrm{dl}$.

$\S$ Minimum glucose less than $30 \mathrm{mg} / \mathrm{dl}$ or less than $40 \mathrm{mg} / \mathrm{dl}$ associated with significant symptoms.

\| Glucose increase of $<15 \mathrm{mg} / \mathrm{dl}$ after 2-deoxyglucose. 
10 of the children had no evidence of hypoglycemia, four had a possible disorder, and 19 had definite hypoglycemia.

To assess the relative reliability of fasting and 2DG as possible separate initial screening tests for hypoglycemia, the response to each test alone according to the above criteria was compared with the final overall classification. Excluding the siblings who were recruited as possible controls, 29 children were tested because of suspected or known hypoglycemia. According to the criteria, the response to either the fasting test or the 2DG test alone was consistent with the final classification in 25 of the 29 cases $(86 \%)$ (Table 3 ). Among the 11 children without documented spontaneous hypoglycemia, the fasting test was consistent with the final classification in nine cases and the 2DG test in 10 cases. No children with documented spontaneous hypoglycemia were undetected by either test, but in some cases with discrepant test results, it was clear that a persistent abnormality failed to be detected by one of the two tests. No child who responded normally to $2 \mathrm{DG}$ became hypoglycemic beyond the first $24 \mathrm{~h}$ of the fasting test. If both tests were to be performed, a practical approach would be to start with the $2 \mathrm{DG}$ test; if that were normal, it would not be necessary to extend the fasting test for more than $24 \mathrm{~h}$.

It may seem surprising that the acute response to 2DG-simulated hypoglycemia could sufficiently mimic conditions of fasting so as to provide a comparable test. The normal metabolic transition from carbohydrate to fat oxidation during fasting depends initially on decreased insulin and increased glycogenolysis, followed by gradually increasing lipolysis and gluconeogenesis facilitated by increased counter-regulatory hormones $(2,12,15$, 16). The acute response to $2 \mathrm{DG}$, as described above, depends on a selective hypothalamic response to deprivation of glucose and a sympathetic reflex resulting in release of epinephrine and inhibition of insulin. We found previously that the hyperglycemic response to $2 \mathrm{DG}$ is absent in children who cannot produce epinephrine (16). Recent data indicate that the increase in plasma glucose in children after $2 \mathrm{DG}$ is due to decreased glucose utilization rather than increased production (17); therefore, administration of $2 \mathrm{DG}$ stimulates a rapid physiologic counter-regulatory response which may occur more gradually in fasting children as a result of depletion of endogenous sources of glucose.

A difference between responses to the two tests obviously could be related to the mechanism of the hypoglycemic disorder. Both tests have value in the further differential diagnosis of hypoglycemia if additional measurements of circulating substrates and hormones are included. These features are considered in detail in a separate report (11). Among the present 23 subjects with "definite" or "possible" hypoglycemia, three had elevated fasting insulin, seven had primary epinephrine deficiency, one had growth hormone deficiency, one had adrenocortical insufficiency, and 11 did not have a clearly identified abnormality (including all four subjects with a "possible" hypoglycemic disorder). In general, the fasting test was more useful in making the diagnosis of hyperinsulinism, as has been previously described (35), whereas the 2DG test was more reliable in detecting epinephrine deficiency (16). All the subjects with hyperinsulinism, growth hormone deficiency, and adrenal cortical insufficiency had abnormal responses to both tests. Those with epinephrine deficiency all failed to respond to 2DG, but two did not become hypoglycemic while fasting. An increase in epinephrine is necessary but not always sufficient for the hyperglycemic response to 2DG. Abnormalities of other regulatory factors may interfere with a normal epinephrine response, and epinephrine unresponsiveness may be associated with other abnormalities. Among the undifferentiated subjects, seven became hypoglycemic while fasting and eight failed to respond to 2DG. For these reasons, as well as for purposes of initial screening, it is valuable to have the complementary results of both tests. It should be noted that seven infants under age $1 \mathrm{yr}$, with relatively severe fasting hypoglycemia due to hyperinsulinism or various inherited metabolic disorders, were not included in this series because the 2DG test was not performed; use of $2 D G$ is not likely to be beneficial in young infants.

The fasting test is unfortunately a tedious and trying diagnostic procedure. Because the time of onset of possible hypoglycemia and symptoms cannot be anticipated, frequent blood sampling must be continued throughout the test, rapid glucose analysis must be available, and problems must be promptly recognized and addressed. From a practical standpoint, the 2DG test is relatively short and not as difficult for the child, family, and professional staff. The symptoms, which followed administration of 2DG in these patients, were not more severe than those associated with fasting. The observed drop in temperature without increased pulse or blood pressure in the present reference subjects is consistent with previous observations in adults who have been given $2 \mathrm{DG}(9,21,39)$. Intervention was required in one case in which the patient was also simultaneously hypoglycemic; symptoms were reversed by administering glucose. This problem can be avoided by not giving $2 D G$ if the initial plasma glucose is $<60 \mathrm{mg} / \mathrm{dl}$.

Contrary to previous conclusions in the literature (41), competitive inhibition of glucose transport by extracellular 2DG (5), rather than intracellular accumulation of the non-metabolizable product 2-deoxyglucose-6-phosphate $(5,28,37,41)$, is responsible for the acute physiologic effects. As illustrated in the present subjects and previous studies (9), the symptoms and physiologic effects diminish rather than increase as 2DG leaves the extracellular space. Because the rate of disappearance is not adequately accounted for by urinary loss, most of the 2DG must initially enter the intracellular space as 2-deoxyglucose-6-phosphate, and presumably later is gradually dephosphorylated and lost in the urine. Studies in young rats given $800 \mathrm{mg} / \mathrm{kg}$ of $2 \mathrm{DG}$ subcutaneously for $19 \mathrm{~d}$ showed no growth inhibition or other apparent effects, indicating that chronic toxicity is minimal (22). The major disadvantage of using 2DG at present is that it is not readily available for human use and is likely to remain an investigational drug for the foreseeable future because of lack of demand. Although investigational experience with $2 \mathrm{DG}$ has been greater in adults, practical applications for diagnostic use in adults remain limited, including testing intactness of the vasogastric $(7,13)$ and sympathoadrenal reflexes $(1,38)$.

In summary, the $2 D G$ test provides a useful supplement to fasting as a diagnostic tool for detection and confirmation of hypoglycemia in childhood. Neither fasting nor the 2DG test alone is completely definitive, but if both tests are performed it is unlikely that a case of hypoglycemia would be missed. If the 2DG test is done first and is normal, there is no need to extend the fasting test for more than $24 \mathrm{~h}$. If only the fasting test is performed, it should be extended for $36 \mathrm{~h}$ to pick up as many cases of hypoglycemia as possible. Determining blood glucose during spontaneously occurring symptoms remains a valuable means of detecting hypoglycemia. Measurement of various hormones and substrates during both of these tests is valuable in making a differential diagnosis as is described in a separate report (11).

\section{REFERENCES AND NOTES}

1. Brodows, R. G., Pi-Sunyer, F. X., and Campbell, R. G.: Neural control of counter-regulatory events during glucopenia in man. J. Clin. Invest., 52: 1841 (1973).

2. Cahill, G. F., Herrera, M. G., Morgan, A. P., Soeldner, J. S., Steinke, J., Levy, P. L., Reichard, G. A., and Kipnis, D. M.: Hormone-fuel interrelationships during fasting. J. Clin. Invest., 4: 1751 (1966).

3. Chaussain, J. L.: Glycemic response to 24 hour fast in normal children and children with ketotic hypoglycemia. J. Pediatr., 82: 438 (1973).

4. Cornblath, M. and Schwartz, R.: Hypoglycemic syndromes in infancy. In: A. J. Schaffer: Disorders of Carbohydrate Metabolism in Infancy. pp. 356-359 (W. B. Saunders, Philadelphia, 1976).

5. Cramer, F. B. and Woodward, G. E.: 2-Deoxy-D-glucose as an antagonist of glucose in yeast fermentation. J. Franklin Inst., 253: 354 (1952).

6. Cramer, F. B. and Neville, G. A.: A colorimetric method for estimating 2desoxyglucose. J. Franklin Inst., 256: 379 (1953).

7. Duke, W. W., Hirschowitz, B. I., and Sachs, G.: Vagal stimulation of gastric 
secretion in man by 2-deoxy-D-glucose. Lancet 2: 871 (1965).

8. Fajans, S. S. and Floyd, J. C.: Fasting hypoglycemia in adults. N. Engl. J. Med., 294: 766 (1976).

9. Freinkel, N., Metzger, B. E., Harris, E., Robinsonn, S., and Mager, M.: The hypothermia of hypoglycemia: studies with 2-deoxy-D-glucose in normal human subjects and mice. N. Engl. J. Med., 287: 841 (1972).

10. Greenberg, R. E. and Christiansen, R. O.: The critically ill child: hypoglycemia. Pediatrics, 46: 915 (1970).

11. Hansen, I. L., Levy, M. M., and Kerr, D. S.: Differential diagnosis of hypoglycemia in children by responses to fasting and 2-deoxyglucose. Metabolism, 32: 960 (1983).

12. Haymond, M. W., Karl, I. E., Clarke, W. L., Pagliara, A. S., and Santiago, J. V.: Differences in circulating gluconeogenic substrates during short term fasting in men, women, and children. Metabolism, 31: 33 (1982).

13. Hedo, J. A., Villanueva, M., and Marco, J.: Stimulation of pancreatic polypeptide and glucagon secretion by 2-deoxy-D-glucose in man: evidence for cholinergic mediation. J. Clin. Endocrinol. Metab., 47: 366 (1978).

14. Kay, R., Davidson, M. H., Williams, M. L., Kumagai, M., and Picou, D. M.: The response of blood glucose, ketones, and plasma nonesterified fatty acids to fasting and epinephrine injection in infants and children. J. Pediatr., 59: 836 (1961).

15. Kerr, D. S., Stevens, M. C. G., and Robinson, H. M.: Fasting metabolism in infants. I. Effect of severe undernutrition on energy and protein utilization. Metabolism, 27: 411 (1978).

16. Kerr, D. S., Brooke, O. G., and Robinson, H. M.: Fasting energy utilization in the smaller of twins with epinephrine-deficient hypoglycemia. Metabolism, 30: 6 (1981).

17. Kerr, D. S., Kalhan, S., and Tserng, K. Y.: Decreased glucose utilization without increased production following stimulation of epinephrine in children. Pediatr. Res., 15: 633 (1981).

18. Koffler, H., Schubert, W. K., and Hug, G.: Sporadic hypoglycemia: abnormal epinephrine response to the ketogenic diet or to insulin. J. Pediatr., 78: 448 (1971).

19. Kruse, K. and Bartels, H.: Die bedeutung des 2-desoxy-glucose-tests für die differenzierung kindlicher hypoglykamien. Klin. Padiatr., 187: 308 (1975).

20. Kudla, R. M. and McVean, D. E.: Semiquantitative separation of carbohydrates in urine by thin layer chromatography. Am. J. Clin. Pathol., 38: 279 (1968).

21. Landau, B. R., Laszlo, J., Stengle, J., and Burk, D.: Certain metabolic and pharmacologic effects in cancer patients given infusions of 2-deoxy-Dglucose. J. Natl. Can. Inst., 21: 485 (1958)

22. Landau, B. R. and Lubs, H. A.: Animal responses to 2-deoxy-D-glucose administration. Proc. Soc. Exp. Biol. Med., 99: 124 (1958).

23. Laszlo, J., Harlan, W. R., Klein, R. F., Kirshner, N., Estes, E. H., and Bogdonoff, M. D.: The effect of 2-deoxy-D-glucose infusions on lipid and carbohydrate metabolism in man. J. Clin. Invest., 40: 171 (1961).

24. Likuski, H. J., Debons, A. F., and Cloutier, R. J.: Inhibition of gold thioglucoseinduced hypothalamic obesity by glucose analogues. Am. J. Physiol., 212. 669 (1967).

25. Lipman, R. L., Ulvedal, F., Schnure, J. J., Bradley, E. M., and Lecocq, F. R.: Gluco-regulatory hormone response to 2-deoxy-D-glucose infusion in normal subjects at bedrest. Metabolism, 19:980 (1970).

26. Merimee, T. J. and Tyson, J. E.: Hypoglycemia in man: pathologic and physiologic variants. Diabetes, 26: 161 (1977).
27. Muller, E. E., Frohman, L. A., and Cocchi, D.: Drug control of hyperglycemia and inhibition of insulin secretion due to centrally administered 2-deoxy-Dglucose. Am. J. Physiol., 224: 1210 (1973).

28. Nirenberg, M. W. and Hogg, J. F.: Inhibition of anaerobic glycolysis in Ehrlich ascites tumor cells by 2-deoxy-D-glucose. Cancer Res., 18: 518 (1958).

29. Pagliara, A. S., Karl, I. E., DeVivo, D. C., Feigin, R. D., and Kipnis, D. M.: Hypoalaninemia: a concomitant of ketotic hypoglycemia. J. Clin. Invest., 51: 1440 (1972).

30. Permutt, M. A.: Postprandial Hypoglycemia. Diabetes, 25: 719 (1976).

31. Pfleiderer, G.: Glycogen: determination as D-glucose with hexokinase, pyruvic kinase, and lactic dehydrogenase. In: H. U. Bergmeyer: Methods of Enzymatic Analysis. pp. 59-62 (New York, Academic Press, 1965).

32. Senior, B. and Loridan, L.: Gluconeogenesis and insulin in the ketotic variety of childhood hypoglycemia and in control children. J. Pediatr., 74: 529 (1969).

33. Sizonenko, P. C., Paunier, L., Vallotton, M. B., Cuendet, G. S., Zahnd, G., and Marliss, E. B.: Response to 2-deoxy-D-glucose and to glucagon in "ketotic hypoglycemia" of childhood: evidence for epinephrine deficiency and altered alanine availability. Pediatr. Res., 7: 983 (1973).

34. Smith, G. P., Gibbs, J., Strohmayer, A. J., and Stokes, P. E.: Threshold doses of 2-deoxy-D-glucose for hyperglycemia and feeding in rats and monkeys. Am. J. Physiol., 222: 77 (1972).

35. Stanley, C. A. and Baker, L.: Hyperinsulinism in infancy: diagnosis by demonstration of abnormal response to fasting hypoglycemia. Pediatrics, 57: 702 (1976).

36. Thompson, D. A., Campbell, R. G., Lilavivat, U., Welle, S. L., and Robertson, G. L.: Increased thirst and plasma arginine vasopressin levels during 2deoxyglucose-induced glucoprivation in humans. J. Clin. Invest., 67: 1083 (1981).

37. Tower, D. B.: The effects of 2-deoxy-D-glucose on metabolism of slices of cerebral cortex incubated in vitro. J. Neurochem., 3: 185 (1958).

38. Wegienka, L. C., Grasso, S. G., and Forsham, P. H.: Estimation of adrenomedullary reserve by infusion of 2-deoxy-D-glucose. J. Clin. Endocrinol. Metab., 26: 37 (1966).

39. Wegienka, L. C., Grodsky, G. M., Karam, J. H., Grasso, S. G., and Forsham, P. H.: Comparison of insulin and 2-deoxy-D-glucose-induced glucopenia as stimulators of growth hormone secretion. Metabolism, 16: 245 (1967).

40. Werner, P. L., Benson, J. W., Brodsky, J. B., Hollander, P. M., Asplin, C. M., Johnson, D. G., and Palmer, J. P.: Comparison of glucagon responses to 2deoxyglucose and hypoglycemia in man. Am. J. Physiol., 239: E227 (1980).

41. Wick, A. N., Drury, D. R., Nakada, H. I., and Wolfe, J. B.: Localization of the primary metabolic block produced by 2 -deoxyglucose. J. Biol. Chem., 224 : 963 (1957).

42. The authors are grateful for the helpful suggestions of Dr. William Dahms.

43. Requests for reprints should be addressed to: Douglas S. Kerr, Rainbow Babies and Childrens Hospital, 2101 Adelbert Rd., Cleveland OH 44106.

44. This research was supported by the Frackelton Fund, the Diabetes Association of Greater Cleveland, and the National Institute of Child Health and Human Development (Grant HD-1 1089) and the General Clinical Research Center (Grant MOI-RR0080).

45. Received for publication March 24, 1982.

46. Accepted for publication July 12, 1983. 